\title{
THE
}

\section{An incipient invasion of brown anole lizards (Anolis sagrei) into their own native range in the Cayman Islands: a case of cryptic back-introduction}

\author{
Jason J. Kolbe \\ University of Rhode Island, jjkolbe@uri.edu \\ Johanna E. Wegener \\ University of Rhode Island \\ Yoel E. Stuart \\ Ushuaia Milstead \\ University of Rhode Island \\ Katherine E. Boronow
}

The University of Rhode Island Faculty have made this article openly available.

Please let us know how Open Access to this research benefits you.

This is a pre-publication author manuscript of the final, published article.

Terms of Use

This article is made available under the terms and conditions applicable towards Open Access

Policy Articles, as set forth in our Terms of Use.

Citation/Publisher Attribution

Kolbe, J.J., Wegener, J.E., Stuart, Y.E. et al. Biol Invasions (2017) 19: 1989. https://doi.org/10.1007/ s10530-017-1432-2

Available at: https://doi.org/10.1007/s10530-017-1432-2 


\section{Authors}

Jason J. Kolbe, Johanna E. Wegener, Yoel E. Stuart, Ushuaia Milstead, Katherine E. Boronow, Alexis S. Harrison, and Jonathan B. Losos 
1

1 An incipient invasion of brown anole lizards (Anolis sagrei) into their own native range in the

2 Cayman Islands - a case of cryptic back-introduction

3

4 Jason J. Kolbe ${ }^{1, *}$, Johanna E. Wegener ${ }^{1}$, Yoel E. Stuart ${ }^{2,3}$, Ushuaia Milstead ${ }^{1}$, Katherine E.

5 Boronow $^{2}$, Alexis S. Harrison ${ }^{2}$, and Jonathan B. Losos ${ }^{2}$

6

$7 \quad{ }^{1}$ Department of Biological Sciences, University of Rhode Island, 120 Flagg Road, Kingston, RI

$8 \quad 02881$

$9{ }^{2}$ Department of Organismic and Evolutionary Biology and Museum of Comparative Zoology,

10 Harvard University, 26 Oxford Street, Cambridge, MA 02138

$11{ }^{3}$ Present address: Department of Integrative Biology, University of Texas at Austin, 2401

12 Speedway, Austin, TX 78712

13

$14 *$ Corresponding Author email: jjkolbe@uri.edu

15

16 ABSTRACT

17 Human-mediated dispersal has reshaped distribution patterns and biogeographic

18 relationships for many taxa. Long-distance and over-water dispersal were historically rare events

19 for most species, now human activities can move organisms quickly over long distances to new

20 places. An eventual consequence of human activities is the potential reintroduction of

21 individuals from an invasive population back into their native range; a dimension of biological

22 invasion termed "cryptic back-introduction." We investigated whether this phenomenon was

23 occurring in the Cayman Islands where brown anole lizards (Anolis sagrei) with red dewlaps 
24 (i.e., throat fans), either native to Little Cayman or invasive on Grand Cayman, have been found 25 on Cayman Brac where the native A. sagrei have yellow dewlaps. Our analysis of microsatellite

26 data shows strong population-genetic structure among the three Cayman Islands, but also

27 evidence for non-equilibrium. We found some instances of intermediate multilocus genotypes

28 (3-9\% of individuals), particularly between Grand Cayman and Cayman Brac. Furthermore, 29 analysis of dewlap reflectance data misclassified some males sampled on Cayman Brac as 30 having red dewlaps similar to lizards from Grand Cayman and Little Cayman. Lastly, one 31 individual from Cayman Brac had an intermediate microsatellite genotype, a red dewlap, and a 32 mtDNA haplotype from Grand Cayman. This mismatch among genetic and phenotypic data 33 documents that invasive A. sagrei from Grand Cayman are interbreeding with native A. sagrei on 34 Cayman Brac. To our knowledge, this is the first evidence of "cryptic back-introduction." 35 Although we clearly demonstrate this phenomenon is occurring in the Cayman Islands, assessing 36 its frequency there and prevalence in other systems may prove difficult due to the need for 37 genetic data. Cryptic back-introductions may eventually provide some insight into how the 38 invasion process changes a lineage as compared to how evolution shaped the lineage in its native 39 range.

\section{KEYWORDS}

42 admixture; dewlap; microsatellites; nuclear-mitochondrial mismatch; reproductive isolation 43 


\section{INTRODUCTION}

45 In this era of widespread human-mediated dispersal, geographic distance is no longer a

46 barrier to movement for many species. Exotic species introductions have altered fundamental

47 biogeographic patterns such as species-area and species-isolation relationships (MacArthur \&

48 Wilson 1963; Sax et al. 2005). For example, colonization by exotic Anolis lizards in the

49 Caribbean has altered pre-invasion biogeographic patterns (Losos \& Schluter 2000), effectively

50 reducing geographic isolation among islands and flattening the negative species-isolation

51 relationship for anoles (Helmus et al. 2014). Long-distance colonization events due to human

52 activity can bring together evolutionarily distinct lineages that in some instances have been

53 separated for millions of years. Novel interactions among these lineages could reshape existing

54 ecological communities and alter patterns of species diversity (e.g., Stuart et al. 2014; Liu et al.

55 2014). Furthermore, hybridization or admixture between introduced and native taxa (e.g.,

56 Fitzpatrick \& Shaffer 2007) might compromise the genetic distinctiveness of taxa, including

57 endemics, unique phenotypes, and evolutionarily significant units (Moritz 1994). A previously

58 undocumented dimension of biological invasion could occur when invasive populations from

59 outside of their native range are reintroduced into native-range populations. Guo (2005)

60 proposed the term "cryptic back-introduction" for this phenomenon, but to our knowledge it has

61 never been demonstrated. Here we explore whether this phenomenon is occurring in the brown

62 anole lizard (Anolis sagrei) and consider the implications of this type of invasion for native 63 populations.

64 Anolis sagrei is a good natural colonizer, reaching many islands and mainland areas in 65 the Caribbean by overwater dispersal (Williams 1969). During its $\sim 6.5$ million year evolutionary 66 history (R.G. Reynolds, pers. comm.), this species colonized all of Cuba, most islands in the 
67 Bahamas, the Atlantic coast of Mexico and Belize, and Swan Island (Schwartz \& Henderson

68 1991). Approximately 2.5 million years ago this species also colonized Cayman Brac and Little

69 Cayman (R.G. Reynolds, pers. comm.), two small and relatively remote islands in the western

70 Caribbean. Subsequently, A. sagrei differentiated into the yellow-dewlapped endemic subspecies

71 A. s. luteosignifer on Cayman Brac and the red-dewlapped A. s. sagrei on Little Cayman

72 (Schwartz \& Henderson 1991); the dewlap is an extendable throat fan used for communication in

73 anoles (Losos 2009). However, A. sagrei failed to colonize the third of the Cayman Islands,

74 Grand Cayman, which is located $\sim 100 \mathrm{~km}$ to the southwest of the other Cayman Islands. That is,

75 until the early1980s when a red-dewlapped form of A. sagrei became established on Grand

76 Cayman via a human-mediated introduction on cargo shipments from established non-native

77 populations in South Florida (Minton \& Minton 1984; Kolbe et al. 2004; Fig. 1), thereby

78 accomplishing a long-distance dispersal event that failed to occur naturally. Since this time,

79 inter-island supply shipments by air and sea within the Caymans - primarily from the capital and

80 largest port on Grand Cayman $\left(196 \mathrm{~km}^{2}\right)$ to the much smaller Cayman Brac $\left(\sim 38 \mathrm{~km}^{2}\right)$ and Little

81 Cayman $\left(<10 \mathrm{~km}^{2}\right)$ —could have transported invasive and native A. sagrei among this trio of

82 islands. Indeed, in 2010, a single A. sagrei individual with a red dewlap was observed on

83 Cayman Brac (T. Sanger, pers. comm.), suggesting an introduction of invasive A. sagrei from

84 Grand Cayman or native A. s. sagrei from Little Cayman.

85 In this study, we surveyed A. sagrei populations across Cayman Brac looking for red-

86 dewlapped lizards to determine whether invasive A. sagrei from Grand Cayman have in fact

87 invaded Cayman Brac. We also collected lizards on Grand Cayman and Little Cayman to

88 discriminate between these two potential sources of red-dewlapped A. sagrei. For lizards from

89 all three islands, we quantified dewlap phenotypes using spectrophotometric methods, measured 
90 structural habitat use (i.e., perch height and diameter) and body size (i.e., snout-vent length

91 [SVL], and mass), and genotyped 10 nuclear microsatellite loci. For individuals with

92 intermediate multilocus genotypes or a genotype that did not match their island, we sequenced

93 mtDNA haplotypes (ND2) to test for nuclear-mitochondrial mismatches. Using these data, we

94 evaluated whether invasive A. sagrei from Grand Cayman have been introduced to native

95 populations on Cayman Brac, and if so, whether invasive lizards have interbred with native

96 lizards.

97

98 METHODS

99 We sampled lizards in the Cayman Islands in January 2011, focusing the majority of our 100 effort on Cayman Brac due to the previous observation of a red-dewlapped A. sagrei there (Fig. 1

$101 \&$ Table S1). On all three islands, for each undisturbed lizard encountered, we measured perch 102 height $(\mathrm{cm})$ and perch diameter $(\mathrm{cm})$, two key aspects of the structural habitat niche in anoles 103 (Losos 2009). We also measured two aspects of body size, SVL (mm) and mass (g), for all 104 lizards captured. We caught only males because females do not have dewlaps (see below). We 105 used analysis of variance (ANOVA) to test for differences among islands in lizard structural 106 habitat use and body size using JMP (SAS 2014). Perch diameter values were log-transformed 107 to achieve a normal distribution.

108 To quantify dewlap color, we measured reflectance spectra from 300 to $700 \mathrm{~nm}$ in 109 wavelength (i.e., visible plus ultraviolet light) using an Ocean Optics USB4000 110 spectrophotometer with a pulsed Xenon light source (PX-2, Ocean Optics), calibrated regularly 111 against a white reflectance standard (Labsphere, Inc.). We measured reflectance at nine points 112 distributed across the dewlap by pressing the dewlap against a black background with the 
113 reflectance probe containing a black, $45^{\circ}$-angled tip used to prevent specular glare. The Ocean

114 Optics software was set to a boxcar width of five and an integration time of ten milliseconds. We

115 averaged ten scans to generate spectra for each point on the dewlap.

We used the R-package pavo (Maia 2013) to manipulate spectrophotometric data.

Briefly, we used the functions getspec to import our spectra within the 300-700 nm wavelength window, aggspec to generate a mean spectrum for each individual, and procspec to bin those spectra into $10-\mathrm{nm}$ windows. With the values from these 10-nm bins, we used the base package R-function prcomp to conduct a principal component analysis (PCA) in R (R Core Team 2014). 121 We tested for differences among islands on PC axes representing dewlap reflectance using 122 ANOVA and Tukey's Honestly Significant Difference (HSD) post hoc tests using JMP (SAS 123 2014). We then used discriminant function analysis (DFA) to predict group membership based 124 on dewlap reflectance data from PC axes using JMP (SAS 2014). Lizards from Grand Cayman 125 and Little Cayman were combined a priori into a red dewlap group and Cayman Brac lizards 126 were in the yellow dewlap group.

After dewlap data were collected, we removed $\sim 15 \mathrm{~mm}$ of tail tissue for genetic analysis.

128 The tissues were preserved in $100 \%$ ethanol and stored at $-20^{\circ} \mathrm{C}$. We extracted genomic DNA 129 following a standard protocol using the AutoGenprep 965 machine (Autogen, Inc.) in the Bauer 130 Core Facility at Harvard University. We amplified 10 microsatellite loci using PCR (Bardeleben 131 et al. 2004; Wordley et al. 2011) and fluorescently labeled primers following standard protocols 132 at the University of Rhode Island. Samples were genotyped at the DNA Analysis Facility at Yale 133 University. Markers for all samples were analyzed with the software GeneMapper® v4.1 and 134 visually inspected for accuracy. For a subset of individuals, we sequenced the mtDNA marker 135 ND2. Sequences were assembled and aligned in Geneious Pro v5.6.3 (Kearse et al. 2012). Data 
136

137

138

3

4140

8

9142

20

1

2

3

4144

145

146

147

148

149

150

0

1

42

43

44

45

46

47

48

49

50

51

52

53

54

were combined with previously published microsatellite genotypes (Kolbe et al. 2008) and mtDNA (ND2) sequences for the Cayman Islands (Kolbe et al. 2004, 2007).

Using these multilocus microsatellite data, we estimated standard population genetic

statistics for diversity within islands and tested for Hardy-Weinberg equilibrium for each locus

on each island. To evaluate population differentiation among the three islands under the

assumption of Hardy-Weinberg equilibrium, we calculated pairwise F $_{\text {ST }}$ values using GenAlEx

(Peakall \& Smouse 2012) and conducted a Bayesian cluster analysis using STRUCTURE

(Pritchard et al. 2000). We also assessed population differentiation among islands with methods

that do not rely on assumptions of equilibrium, including principal coordinates analysis (PCoA)

using GenAlEx and discriminant analysis of principal components (DAPC) using the adegenet

package in R (Jombart \& Ahmed 2012). To determine the relationships among ND2 haplotypes, we constructed a maximum likelihood phylogeny using RAxML (Stamatakis et al. 2008;

Silvestro \& Michalak 2012). The final alignment consisted 540 bp of ND2 for 63 individuals, including samples from the Cayman Islands, Cuba, South Florida and A. bremerei as the outgroup (Kolbe et al. 2007). We used GTR $+\mathrm{G}$, the best fitting available model for nucleotide substitution based on Modeltest 3.7 (Posada \& Crandall 1998). For the ML search, we used the rapid bootstrapping algorithm with 1000 non-parametric replicates.

154 RESULTS

155 We sampled a total of 280 male A. sagrei from 18 sites on Cayman Brac ( $\mathrm{n}=195)$, two 156 sites on Little Cayman ( $\mathrm{n}=26$ ), and six sites on Grand Cayman ( $\mathrm{n}=59)$ (Fig. 1 \& Table S1). We 157 found no differences among islands in structural habitat use (perch height: $\mathrm{F}_{2,201}=1.32, \mathrm{P}=0.27$ 158 and log-perch diameter: $\mathrm{F}_{2,173}=0.32, \mathrm{P}=0.73$ ) or body size ( $\mathrm{SVL}: \mathrm{F}_{2,254}=0.02, \mathrm{P}=0.98$ and mass: 
$\mathrm{F}_{2,241}=2.38, \mathrm{P}=0.10 ;$ Table $\mathrm{S} 2$ ). When comparing $\mathrm{PC}$ axes, dewlap reflectance showed strong

differentiation between yellow-dewlapped lizards on Cayman Brac and the red-dewlapped

161 lizards on the other two islands (Fig. 2 \& Table 1A). DFA based on PC axes 1-4, which

represented 98\% of variation, misclassified six lizards (CB008, CB026, CB046, CB107, CB170, 163 CB178), all of which were sampled on Cayman Brac but classified as having a red dewlap (Fig. 164 2). This supports our field observations of seemingly red-dewlapped lizards occurring on 165 Cayman Brac (Fig. 3) and suggests the introduction of invasive A. sagrei from Grand Cayman or 166 native A. s. sagrei from Little Cayman. One lizard from Little Cayman was misclassified as 167 being from Cayman Brac (LC015).

Cayman Brac had higher allelic diversity compared to the other two islands and Hardy-

Weinberg equilibrium was rejected for most loci on this island (Table 2); both results are consistent with an ongoing influx of alleles to Cayman Brac. F $_{\text {ST values showed greater }}$ differentiation between Grand Cayman and the other two islands $\left(\mathrm{F}_{\mathrm{ST}}=0.209-0.235\right)$ compared to that between Cayman Brac and Little Cayman ( $\mathrm{F}_{\mathrm{ST}}=0.161$; Table S3). Moreover, STRUCTURE identified two genetic clusters corresponding to 1) Grand Cayman and 2) Cayman Brac and Little Cayman (Fig. S1). However, rejection of HWE for half the loci across islands (Table 2) violates the assumption of equilibrium for $\mathrm{F}_{\mathrm{ST}}$ and STRUCTURE analyses. Avoiding this assumption, comparison of PCo axes from multilocus microsatellite genotypes and genetic differentiation based on DAPC analysis showed similarly strong differentiation among islands (Figs. $4 \&$ S2; Table 1B), particularly Grand Cayman compared to the other two islands. We identified genetically intermediate individuals on the PCo 1 v. PCo 2 plot (Fig. 4) as those outside of the $99.7 \%$ confidence ellipse (i.e., 7 of 280 individuals, or 3\%; CB007, CB101, CB104, CB109, CB118, CB144, GC066) or the 95\% confidence ellipse (i.e., 25 of 280 
182 individuals, or 9\%). Most lizards with intermediate microsatellite genotypes were sampled on 183 Cayman Brac and all but one had mtDNA haplotypes matching their island. One lizard sampled 184 on Cayman Brac (CB008) had a Grand Cayman mtDNA haplotype (see phylogenetic tree in Fig. 185 S3), an intermediate genotype outside 95\% confidence ellipse for Cayman Brac, and a red 186 dewlap misclassified in the DFA (Figs. 2-4). Another individual sampled on Cayman Brac 187 (CB101) had a microsatellite genotype indistinguishable from other Little Cayman lizards, yet it 188 had a Cayman Brac mtDNA haplotype and a yellow dewlap (Figs. 2 \& 4). These two examples

demonstrate that red-dewlapped lizards from both Grand Cayman and Little Cayman have been introduced to Cayman Brac and have subsequently interbred with endemic A. s. luteosignifer

191 there. In addition to these definitive examples, numerous individuals show some mismatch 192 among their microsatellite genotype, mtDNA haplotype, and dewlap phenotype. For instance, 193 most lizards from Cayman Brac with misclassified red dewlaps had unambiguously Cayman 194 Brac microsatellite genotypes and mtDNA haplotypes.

\section{DISCUSSION}

197 Our genetic and phenotypic data document for the first time the reintroduction of 198 individuals from an invasive population back into their native range, termed "cryptic back199 introduction" (Guo 2005). Nuclear-mitochondrial mismatches clearly demonstrate that red200 dewlapped A. sagrei from both Grand Cayman and Little Cayman have interbred with endemic, 201 yellow-dewlapped A. s. luteosignifer on Cayman Brac. This supports human-mediated gene flow 202 among islands in the Caymans, including transfer of invasive A. sagrei from Grand Cayman to 203 native populations on Cayman Brac. Although demonstrative, the two lizards with nuclear204 mitochondrial mismatches $(<1 \%)$ could represent merely a low incidence of invasion. 
Alternatively, when including genetic intermediates and lizards with misclassified dewlaps, 4$11 \%$ of lizards may be the product of admixture between invasive and native populations. Less

clear is when and how many times A. sagrei has arrived on Cayman Brac over the past $\sim 30$ years since it invaded Grand Cayman, making it difficult to assess whether invasive alleles are persisting on Cayman Brac or merely being introduced repeatedly.

When invasive individuals from outside of their native range are introduced into a native population at least two outcomes are possible. First, invasive and native lineages may fail to interbreed, and therefore represent cryptic species. Given that the two species will overlap substantially in their ecological niches, interspecific interactions such as competition may be important. If the invader is favored, then the persistence of the native species may be in jeopardy. 215 Alternatively, if the native lineage is favored in interspecific interactions, then the native range 216 may be a sink for propagules that arrive but whose alleles do not persist. A second possibility is 217 that the lineages interbreed, altering the genetic distinctiveness of the native populations. This 218 occurred when introduced tiger salamanders (Ambystoma tigrinum) hybridized with threatened 219 California tiger salamanders (Ambystoma californiense), leading to changes in fitness, population 220 viability, and patterns of natural selection that favored some invasive alleles (Fitzpatrick \& 221 Shaffer 2007; Fitzpatrick et al. 2010). Given genetic admixture of A. sagrei among 222 geographically and genetically distinct native-range lineages during its invasion of Florida 223 (Kolbe et al. 2004, 2008), successful interbreeding among invasive and native lineages in the 224 Caymans is not surprising. In this instance, however, interbreeding occurred despite clear 225 differences in dewlap color, a trait used for species recognition in anoles (Losos 2009) and 226 therefore could have served as a reproductive barrier between lineages. The genetic mixing of 227 these lineages raises the pressing issue of how invasive A. sagrei, which are genetically and 
phenotypically divergent from native lineages (Kolbe et al. 2004, 2007, 2014), will alter the previously isolated populations on Cayman Brac.

The very nature of cryptic back-introductions makes it difficult to identify this

phenomenon based on morphology alone, requiring genetic analyses in most instances. Invaders may harbor other types of phenotypic variation, such as in behavior or physiology, relevant for invasion success. A classic example of a cryptic invasion is the replacement of native common reed (Phragmites australis) haplotypes in New England by a non-native haplotype over the past 100 years (Saltonstall 2002). The spread of this invasive haplotype is at least in part due to greater salinity tolerance and higher relative growth rates compared to native haplotypes (Vasquez et al. 2005), providing a mechanistic explanation for this invasion. Some aspects of phenotypic variation in invasive A. sagrei populations in Florida, including body size, head and limb proportions, and perhaps metabolic rate, are related to the invasion history and source populations (Kolbe et al. 2007, 2014). Other phenotypes like low-temperature tolerance and water loss rate, which follow clines in temperature and moisture in Florida, are suggestive of 242 adaptive responses (Kolbe et al. 2012, 2014). South Florida is the source of the Grand Cayman 243 introduction (Kolbe et al. 2004), so whether these traits or others differ between invasive Grand 244 Cayman A. sagrei and native lizards on Cayman Brac remains to be seen.

245 Our findings show that lizards with different colored dewlaps can interbreed; however, 246 our data are insufficient to determine confidently whether assortative mating and asymmetric 247 introgression are occurring or if mating is random. Females of this species do not have dewlaps, 248 thus males cannot use this trait for mate choice. Unlike other Anolis species that have stereotyped 249 display patterns used during courtship (e.g., Anolis carolinensis; DeCourcy \& Jenssen 1994; 250 Losos 2009), male A. sagrei may lack courtship-specific displays on which females could base 
mate selection (Scott 1984). However, dewlap color and other courtship behaviors could faithfully signal the origin or genetic identity of a male lizard, but little is known about mate selection based on intraspecific variation in anoles. Our preliminary assessment of cyto-nuclear disequilibrium in genetically and phenotypically intermediate lizards from Cayman Brac shows only one case of a lizard with a Grand Cayman mtDNA haplotype (which is maternally derived), suggesting a higher frequency of mating between red-dewlapped males from Grand Cayman or Little Cayman and females from Cayman Brac.

The evolutionary history of isolated island groups has been largely contingent upon rare, long-distance dispersal events (Gillespie \& Clague 2009). Periods of isolation promote divergence that leads to reproductive isolation and eventually speciation. It took A. sagrei millions of years to colonize Cayman Brac and Little Cayman naturally. In contrast, after finally invading Grand Cayman via human-mediated dispersal, invasive A. sagrei spread via human 263 activity to native populations on Cayman Brac within just 30 years. As human commerce in the 264 Anthropocene decreases the "distances" among islands (Helmus et al. 2014), these types of 265 cryptic back-introductions are expected to increase in frequency. If inter-island introductions in 266 the Caymans continue, or even increase, we predict the Cayman Brac lineage will lose its unique 267 genetic and phenotypic identity. Unfortunately, the cryptic nature of back-introductions makes 268 them difficult to monitor without genetic analyses. We therefore do not yet know the frequency 269 with which cryptic back-introductions are occurring. Interbreeding will likely blend traits, like 270 dewlap color, that could contribute to species recognition, potentially derailing speciation and 271 contributing to homogenization (McKinney \& Lockwood 1999). Cryptic back-introductions may 272 eventually provide some insight into whether the process of invasion changes lineages in ways 273 that make them distinct from and potentially incompatible with conspecific native populations. 


\section{ACKNOWLEDGEMENTS}

8

276 We thank Haley Moniz, Vikram Chhatre, Brianne Neptin, Melissa Losos, Bonnie Edwards, and

277 the URI Genome and Sequencing center staff for assistance. Permits were graciously provided 4278 by Matthew Cottam and the Department of Environment of the Cayman Islands. Funding was 279 provided by a Putnam Expeditionary Grant from the Museum of Comparative Zoology, and the 280 University of Rhode Island. 


\section{REFERENCES}

Bardeleben C, Palchevskiy V, Calsbeek R, Wayne RK (2004) Isolation of polymorphic tetranucleotide microsatellite markers for the brown anole (Anolis sagrei). Mol Ecol Notes 4:176-178.

DeCourcy KR, Jenssen TA (1994) Structure and use of male territorial headbob signals by the lizard, Anolis carolinensis. Anim Behav 47:251-262.

Fitzpatrick BM, Shaffer HB (2007) Hybrid vigor between native and introduced salamanders raises new challenges for conservation. Proc Nat Acad Sci 104:15793-15798

Fitzpatrick BM, Johnson JR, Kump DK, Smith JJ, Voss SR, Shaffer HB (2010) Rapid spread of invasive genes into a threatened native species. Proc Nat Acad Sci 107:3606-3610

Gillespie R, Clague D, eds (2009) Encyclopedia of Islands. University of California Press, Berkelely, CA

Guo Q (2005) Possible cryptic invasion through "back introduction"? Frontiers Ecol Environ $3: 470-471$

Helmus, MR, Mahler DL, Losos JB (2014) Island biogeography of the Anthropocene. Nature 513:543-6

Jombart T, Ahmed I (2012) Adegenet: an R package for the exploratory analysis of genetic and genomic data. Available via http://adegenet.r-forge.r-project.org. R package version 1.3.4.

Kearse M, Moir R, Wilson A, Stones-Havas S, Cheung M, Sturrock S, Buxton S, Cooper A, Markowitz S, Duran C, Thierer T, Ashton B, Mentjies P, Drummond A (2012) Geneious Basic: an integrated and extendable desktop software platform for the organization and analysis of sequence data. Bioinformatics 28:1647-1649.

Kolbe JJ, Glor RE, Rodriguez-Schettino L, Chamizo-Lara A, Larson A, Losos JB (2004) Genetic variation increases during biological invasion by a Cuban lizard. Nature 431:177-181

Kolbe JJ, Larson A, Losos JB (2007) Differential admixture shapes morphological variation among invasive populations of the lizard Anolis sagrei. Mol Ecol 16:1579-1591

Kolbe JJ, Larson A, Losos JB, de Queiroz K (2008) Admixture determines genetic diversity and population differentiation in the biological invasion of a lizard species. Biol Lett 4:434-437

Kolbe JJ, VanMiddlesworth PS, Losin N, Dappen N, Losos JB (2012) Climatic niche shift predicts thermal trait response in one but not both introductions of the Puerto Rican lizard Anolis cristatellus to Miami, Florida, USA. Ecol Evol 2:1503-1516 
Kolbe JJ, Ehrenberger JC, Moniz HA, Angilletta MJ (2014) Physiological variation among invasive populations of the Brown Anole (Anolis sagrei). Physiol Biochem Zool 87:92-104.

Liu X, Li X, Liu Z, Tingley R, Kraus F, Guo Z, Li Y (2014) Congener diversity, topographic heterogeneity and human-assisted dispersal predict spread rates of alien herpetofauna at a global scale. Ecol Lett 17:821-829.

Losos JB (2009) Lizards in an Evolutionary Tree: Ecology and Adaptive Radiation of Anoles. University of California Press, Berkelely, CA

Losos JB, Schluter D (2000) Analysis of an evolutionary species-area relationship. Nature 408:847-850

MacArthur RH, Wilson EO (1963) An equilibrium theory of insular zoogeography. Evolution $17: 373-387$

Maia R, Eliason CM, Bitton P-P, Doucet SM, Shawkey MD (2013) pavo: an R package for the analysis, visualization and organization of spectral data. Methods Ecol Evol 4:906-913

McKinney ML, Lockwood JL (1999) Biotic homogenization: a few winners replacing many losers in the next mass extinction. Trends Ecol Evol 14:450-453.

Minton SA, Minton MR (1984) Anolis sagrei (brown anole). Herpetol Rev 15:77

Moritz C (1994) Defining 'evolutionary significant units' for conservation. Trends Ecol Evol 9:373-375.

Peakall R, Smouse PE (2012) GenAlEx 6.5: genetic analysis in Excel. Population genetic software for teaching and research—an update. Bioinformatics 28:2537-2539.

Pritchard JK, Stephens M, Donnelly P (2000) Inference of population structure using multilocus genotype data. Genetics 155:945-959.

Posada D, Crandall, KA (1998) Modeltest: testing the model of DNA substitution. Bioinformatics 14:817-818.

R Core Team (2014) R: A language and environment for statistical computing. R Foundation for Statistical Computing, Vienna, Austria. Available from http://www.R-project.org/

Saltonstall K (2002) Cryptic invasion by a non-native genotype of the common reed, Phragmites australis, into North America. Proc Nat Acad Sci 99:2445-2449

SAS Institute, Inc. (2014) JMP 11.1 Cary, NC 
Sax DF, Brown JH, White EP, Gaines SD (2005) The Dynamics of Species Invasions: insights into the mechanisms that limit species diversity in Species Invasion: insights into ecology, evolution, and biogeography; Sax DF, Stachowicz JJ, Gaines SD, eds. pp. 447-465.

Schwartz A, Henderson RW (1991) Amphibians and Reptiles of the West Indies: Descriptions, Distributions, and Natural History, University of Florida Press, Gainesville, FL

Scott MP (1984) Agonistic and courtship displays of male Anolis sagrei Breviora 479:1-22

Silvestro D, Michalak I (2012) raxmlGUI: a graphical front-end for RAxML. Organisms Diversity \& Evolution 12:335-337.

Stamatakis A, Hoover P, Rougemont, J (2008) A rapid bootstrap algorithm for the RAxML web servers. Syst Biol 57:758-771

Stuart YE, Campbell TS, Hohenlohe PA, Reynolds RG, Revell LJ, Losos JB (2014) Rapid evolution of a native species following invasion by a congener. Science 346: 463-466.

Vasquez EA, Glenn EP, Brown JJ, Guntenspergen GR, Nelson SG (2005) Salt tolerance underlies the cryptic invasion of North American salt marshes by an introduced haplotype of the common reed Phragmites australis (Poaceae). Marine Ecol Prog Series 298:1-8

Williams EE (1969) The ecology of colonization as seen in the zoogeography of anoline lizards on small islands. Quart Rev Biol 44:345-389

Wordley C, Slate J, Stapley J (2011) Mining online genomic resources in Anolis carolinensis facilitates rapid and inexpensive development of cross-species microsatellite markers for the Anolis lizard genus. Mol Ecol Resources 11:126-133 
Fig. 1. Map showing portions of the native and non-native ranges of the brown anole relevant to this study: A) arrows indicate routes of primary invasion from multiple native-range source 404 populations in Cuba to the non-native range in Florida and a secondary invasion from non-native 405 populations in south Florida to Grand Cayman; B) the arrow indicates a cryptic back406 introduction of invasive brown anoles from Grand Cayman into the native range on Cayman 407 Brac; and B \& C) circles show collection localities for genetic, ecological, morphological, and 408 dewlap data on Grand Cayman, Little Cayman, and Cayman Brac with site numbers 409 corresponding to those listed in Table S1.
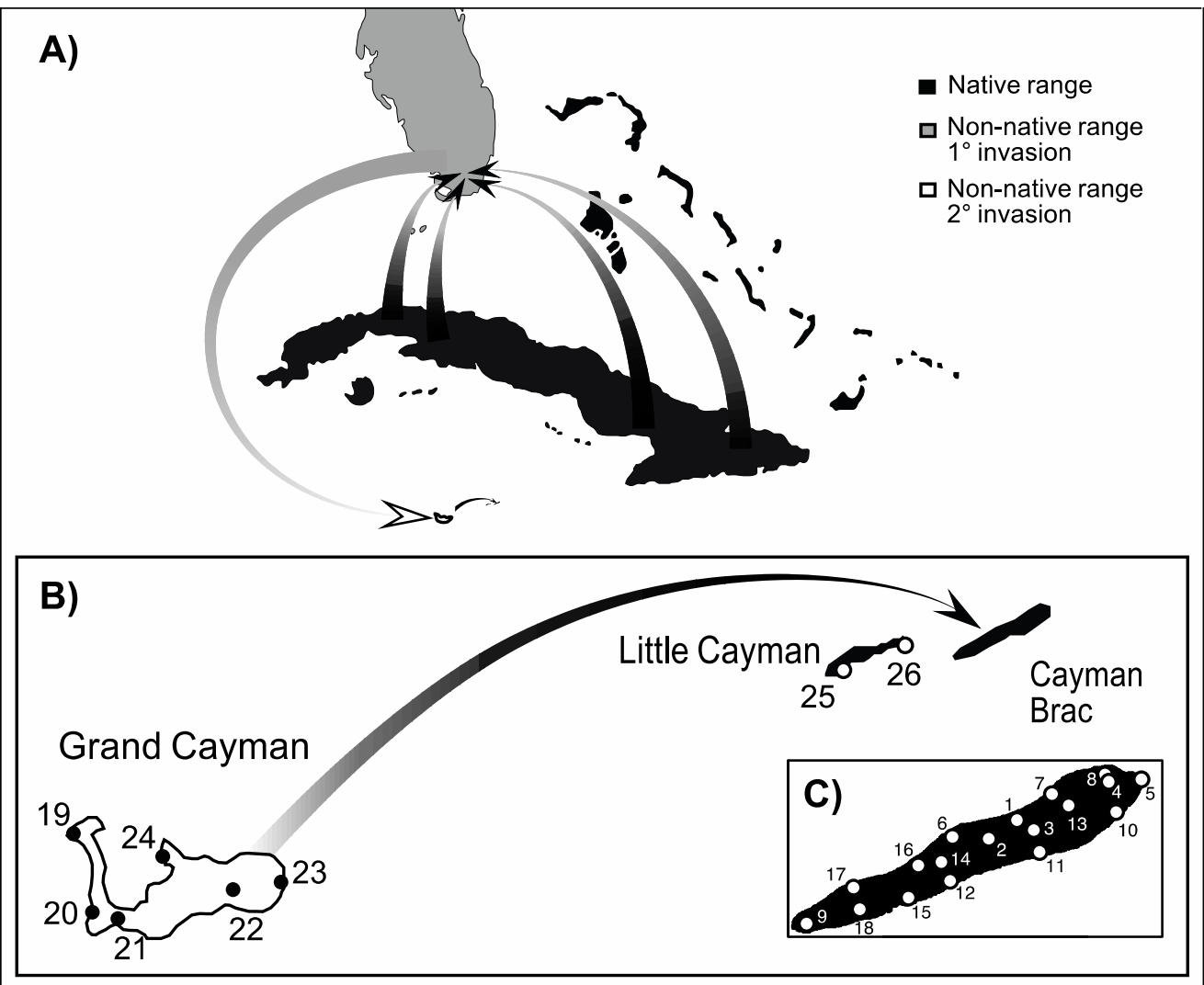
413 Fig. 2. Results of a PCA for dewlap reflectance using the average wavelength from the dewlap 414 of each male lizard. Photos of lizards with their dewlaps extended represent the color variation 9415 along each PC axis.

416

13

14

15

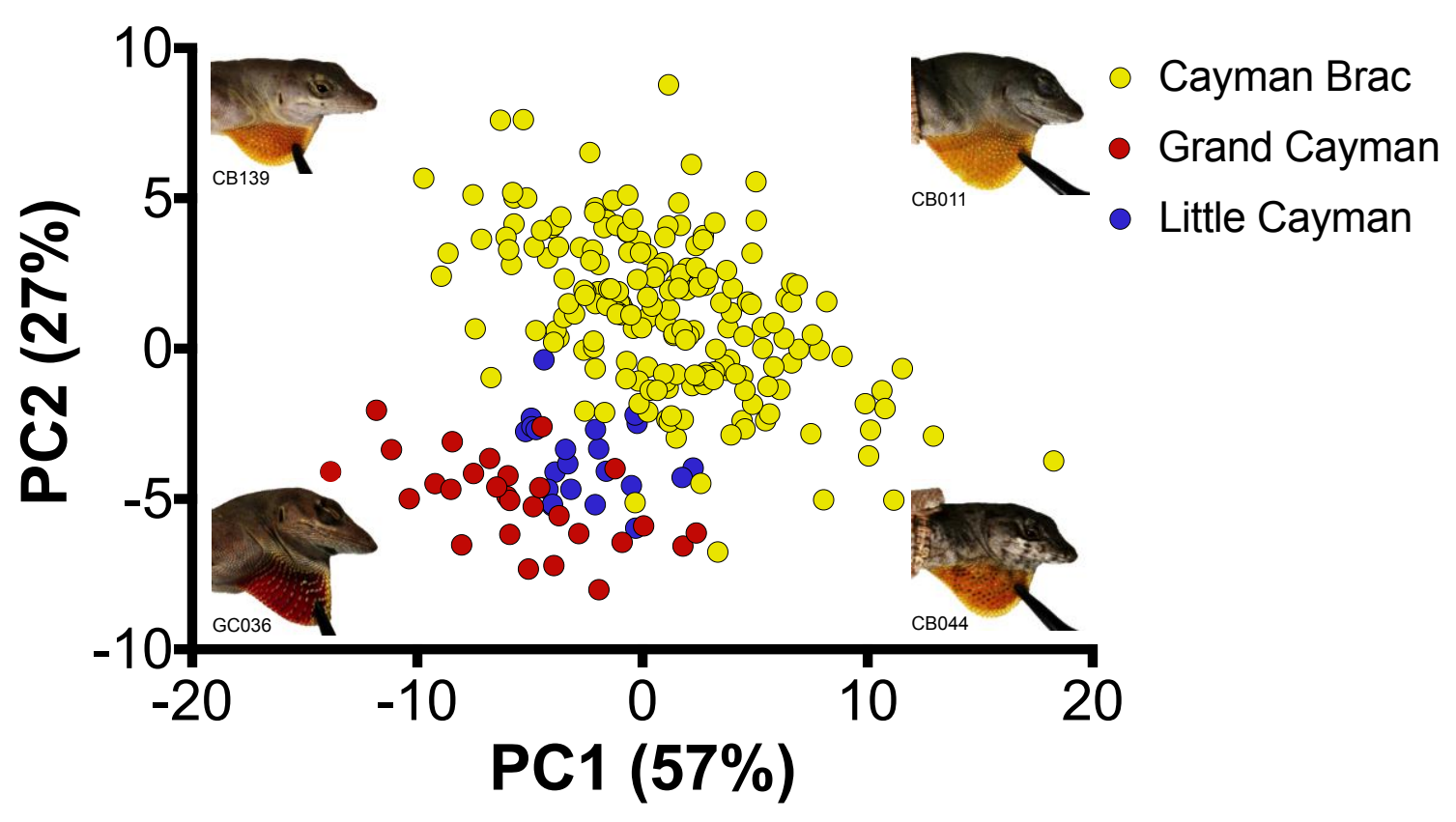


8

Fig. 3. Examples of dewlaps of brown anoles from A) Grand Cayman, B) Cayman Brac with misclassified dewlaps, C) Cayman Brac with intermediate genotypes, D) Cayman Brac with 422 native genotypes, and E) Little Cayman. Genetically intermediate individuals were outside of the $42395 \%$ confidence ellipse for Cayman Brac and intermediate between Cayman Brac and Grand 424 Cayman based on the PCoA of multilocus microsatellite genotypes (see Fig. 4). Misclassified 425 dewlaps were sampled on Cayman Brac, but grouped with red dewlaps (see Fig. 2 and 426 Supplementary Materials for photographic methods).
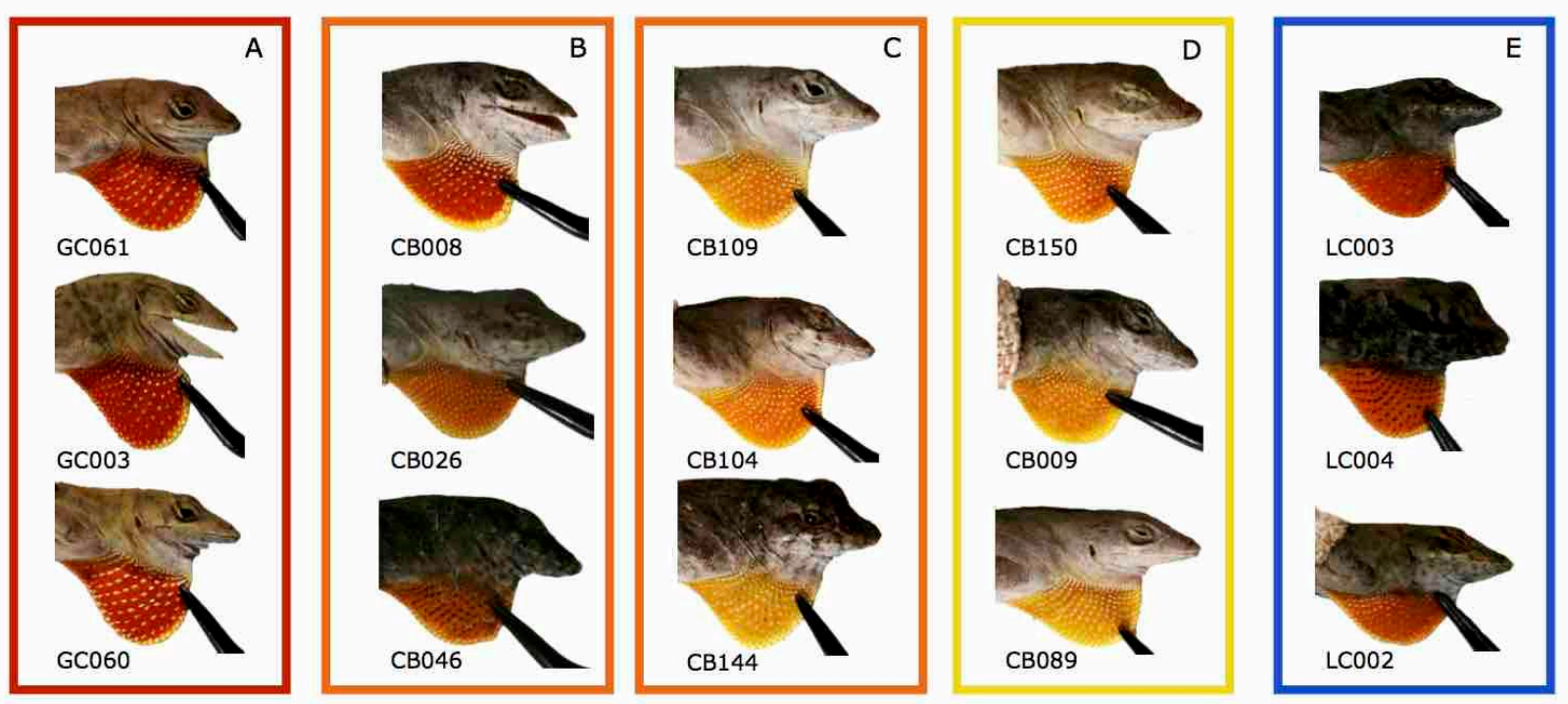
432 Fig. 4. Results of a PCoA using multilocus genotypes from 10 microsatellite loci. Confidence 6

9434 limits are interpreted as individuals that are genetically intermediate between islands. 
438 Table 1. Results of ANOVAs and Tukey's HSD post hoc tests for differences among islands in 439 A) dewlap reflectance based on PC axes $(n=244)$ and B) multilocus microsatellite genotypes 440 based on PCo axes $(n=280)$. Abbreviations are $C B=$ Cayman Brac, $L C=$ Little Cayman, and $441 \mathrm{GC}=$ Grand Cayman.

PC axis

$\mathrm{R}^{2}$

df F

\section{P} variation

\begin{tabular}{lllllll}
\hline PC1 & $57 \%$ & 0.223 & 2,241 & 35.5 & $<0.0001$ & CB $>$ LC $>$ GC \\
PC2 & $27 \%$ & 0.475 & 2,241 & 109.2 & $<0.0001$ & CB $>$ LC $=$ GC \\
PC3 & $8 \%$ & 0.043 & 2,241 & 5.4 & 0.005 & CB $=$ LC $>$ GC \\
PC4 & $4 \%$ & 0.024 & 2,241 & 3.8 & 0.052 & GC $\geq$ CB $\geq$ LC \\
\hline
\end{tabular}

B)

\begin{tabular}{lllllll}
\hline PCo axis & $\begin{array}{l}\text { PCo } \% \\
\text { variation }\end{array}$ & $\mathrm{R}^{2}$ & $\mathrm{df}$ & $\mathrm{F}$ & $\mathrm{P}$ & $\begin{array}{l}\text { Tukey's } \\
\text { HSD }\end{array}$ \\
\hline PCo1 & $42 \%$ & 0.908 & 2,277 & 1363.1 & $<0.0001$ & CB $>$ LC $>$ GC \\
PCo2 & $18 \%$ & 0.530 & 2,277 & 156.4 & $<0.0001$ & $\mathrm{GC}=\mathrm{CB}>$ LC \\
PCo3 & $14 \%$ & 0.049 & 2,277 & 7.1 & 0.001 & $\mathrm{GC}=$ CB $>$ LC \\
PCo4 & $11 \%$ & 0.020 & 2,277 & 2.9 & 0.058 & $\mathrm{GC}=\mathrm{CB}=\mathrm{LC}$ \\
\hline
\end{tabular}


Table 2. Summary statistics for population genetic analyses based on multilocus microsatellite 448 genotypes sampled from the Cayman Islands. $N=$ number of genotypes, $N_{\mathrm{A}}=$ number of alleles, $449 N_{\mathrm{E}}=$ effective number of alleles, $H_{\mathrm{O}}=$ observed heterozygosity, $H_{\mathrm{E}}=$ expected heterozygosity, $450 \quad F_{\text {IS }}=$ fixation index within islands, $H W E=$ number of loci not in Hardy-Weinberg equilibrium $451 \quad(\mathrm{P}<0.05)$. Asterisk $(*)$ indicates that four loci for the Little Cayman population were 452 monomorphic.

\begin{tabular}{|c|c|c|c|c|c|c|c|}
\hline Island & $N$ & $N_{\mathrm{A}}$ & $N_{\mathrm{E}}$ & $H_{\mathrm{O}}$ & $H_{\mathrm{E}}$ & $F_{\text {IS }}$ & $H W E$ \\
\hline Cayman Brac & 195 & $14.1 \pm 3.4$ & $5.32 \pm 1.84$ & $0.44 \pm 0.08$ & $0.55 \pm 0.10$ & $0.22 \pm 0.06$ & $8 / 10$ loci \\
\hline Grand Cayman & 59 & $8.0 \pm 1.1$ & $3.51 \pm 0.38$ & $0.53 \pm 0.06$ & $0.66 \pm 0.06$ & $0.18 \pm 0.07$ & 4/10 loci \\
\hline Little Cayman & 26 & $7.2 \pm 2.4$ & $4.97 \pm 1.68$ & $0.38 \pm 0.12$ & $0.47 \pm 0.14$ & $0.19 \pm 0.07$ & 1/6 loci* \\
\hline Mean & 88.3 & $9.7 \pm 1.5$ & $4.60 \pm 0.82$ & $0.45 \pm 0.05$ & $0.56 \pm 0.06$ & $0.20 \pm 0.04$ & 13/26 loci* \\
\hline
\end{tabular}


462 reference card (Michael Tapes Design). The right side of each lizard's dewlap was extended 463 against an $18 \%$ Delta 1 Gray Card (CPM, Inc.), adjacent to a ruler and a Mini ColorChecker $\AA$ 464 color card (x-rite, Inc.) and photographs were taken without the flash, in a dark room with the 465 lizard illuminated by two 50W Halogena bulbs (Philips, Inc.). Tracing paper was placed in front 466 of the bulbs to diffuse the light and reduce glare. Lizards were immobilized using self-adherent 467 medical wrap and dewlaps were extended with self-closing forceps whose tips were coated with 468 black rubber (Plasti Dip International) to reduce glare.

We collected dewlap data using photographic approaches. Photographs were taken with a Canon Rebel XTi Digital SLR camera set to custom white balance calibrated with a WhiBal ${ }^{\circledR}$ a gainst an $18 \%$ Delta 1 Gray Card (CPM, Inc.), adjacent to a ruler and a Mini ColorChecker color card (x-rite, Inc.) and photographs were taken without the flash, in a dark room with the 
Table S1. Collection localities and sample sizes for brown anoles in the Cayman Islands. Site

\begin{tabular}{|c|c|c|c|c|}
\hline Island & Site (Map ID) & $\begin{array}{c}\text { GPS } \\
\text { Degrees } \\
\mathrm{N}\end{array}$ & $\begin{array}{c}\text { GPS } \\
\text { Degrees } \\
\text { W }\end{array}$ & $\begin{array}{c}\mathrm{N} \\
\text { (Dewlap / } \\
\text { Genetics) }\end{array}$ \\
\hline Cayman Brac & L\&M Superstore (1) & 19.73244 & -79.78450 & $11 / 11$ \\
\hline Cayman Brac & Botanical Garden (2) & 19.72380 & -79.79838 & $12 / 12$ \\
\hline Cayman Brac & Soccer Field (3) & 19.72782 & -79.77621 & $11 / 11$ \\
\hline Cayman Brac & Peter's Cave Overlook (4) & 19.75312 & -79.74110 & $10 / 10$ \\
\hline Cayman Brac & Lighthouse (5) & 19.75124 & -79.72344 & $10 / 10$ \\
\hline Cayman Brac & R\&L Plant Nursery (6) & 19.72461 & -79.81614 & $10 / 10$ \\
\hline Cayman Brac & Port Authority (7) & 19.74444 & -79.76731 & $11 / 11$ \\
\hline Cayman Brac & Peter's Cave Trailhead (8) & 19.75355 & -79.74127 & $11 / 12$ \\
\hline Cayman Brac & Brac Reef Resort (9) & 19.68459 & -79.88777 & $11 / 11$ \\
\hline Cayman Brac & South Road (east end) (10) & 19.73616 & -79.73581 & $14 / 14$ \\
\hline Cayman Brac & South Road (empty lot) (11) & 19.71769 & -79.77339 & $10 / 10$ \\
\hline Cayman Brac & 1758 South Road (12) & 19.70435 & -79.81732 & $10 / 11$ \\
\hline Cayman Brac & Bluff Road (13) & 19.73918 & -79.75911 & $11 / 11$ \\
\hline Cayman Brac & Deadman’s Point Trail (14) & 19.71303 & -79.82159 & $10 / 10$ \\
\hline Cayman Brac & Bat Cave (15) & 19.69661 & -79.83772 & $10 / 10$ \\
\hline Cayman Brac & Cayman Brac Museum (16) & 19.71143 & -79.83292 & $10 / 9$ \\
\hline Cayman Brac & Billy's Supermarket (17) & 19.70124 & -79.86472 & $10 / 11$ \\
\hline
\end{tabular}




\begin{tabular}{|l|l|l|l|l|}
\hline Cayman Brac & Rebekah's Cave (18) & 19.69120 & -79.86161 & $12 / 12$ \\
\hline Grand Cayman & Cayman Turtle Farm (19) & 19.38014 & -81.41726 & $0 / 4$ \\
\hline Grand Cayman & Sunset House (20) & 19.28604 & -81.38998 & $28 / 32$ \\
\hline Grand Cayman & South Coast Hurley's (21) & 19.28156 & -81.34593 & $0 / 5$ \\
\hline Grand Cayman & Queen Elizabeth Botanical Gardens (22) & 19.31614 & -81.16895 & $0 / 8$ \\
\hline Grand Cayman & Sunnyfield Road (23) & 19.32827 & -81.08532 & $0 / 5$ \\
\hline Grand Cayman & Cayman Kai (24) & 19.36738 & -81.27356 & $0 / 5$ \\
\hline Little Cayman & Blossom Village (25) & 19.65912 & -80.08347 & $22 / 26$ \\
\hline Little Cayman & East End (26) & 19.69801 & -79.97370 & $0 / 4$ \\
\hline
\end{tabular}


476 Table S2. Means \pm SD for measurements of body size (SVL and mass) and structural habitat use ${ }_{7}^{6} 477$ (perch height and diameter).

8

478 
4480 Table S3. Pairwise $F_{S T}$ values $( \pm \mathrm{SE})$ comparing the three Cayman Islands with all samples for 481 each island pooled on the off-diagonal and the mean pairwise $F_{S T}$ values $( \pm$ SE) for sampling

\begin{tabular}{cccc}
\hline & Cayman Brac & Grand Cayman & Little Cayman \\
\hline Cayman Brac & $0.042 \pm 0.015$ & & \\
Grand Cayman & $0.209 \pm 0.019$ & $0.071 \pm 0.028$ & \\
Little Cayman & $0.161 \pm 0.023$ & $0.235 \pm 0.019$ & 0.118 \\
\hline
\end{tabular}



9487 and Little Cayman form a single genetic cluster distinct from Grand Cayman. Vertical lines

Fig. S1. Results of the Bayesian cluster analysis using the multilocus microsatellite genotypes indicate that $\mathrm{K}=2$ is the most likely number of genetic clusters. Populations from Cayman Brac represent individuals and results show few individuals with mixed ancestry between the two genetic clusters.

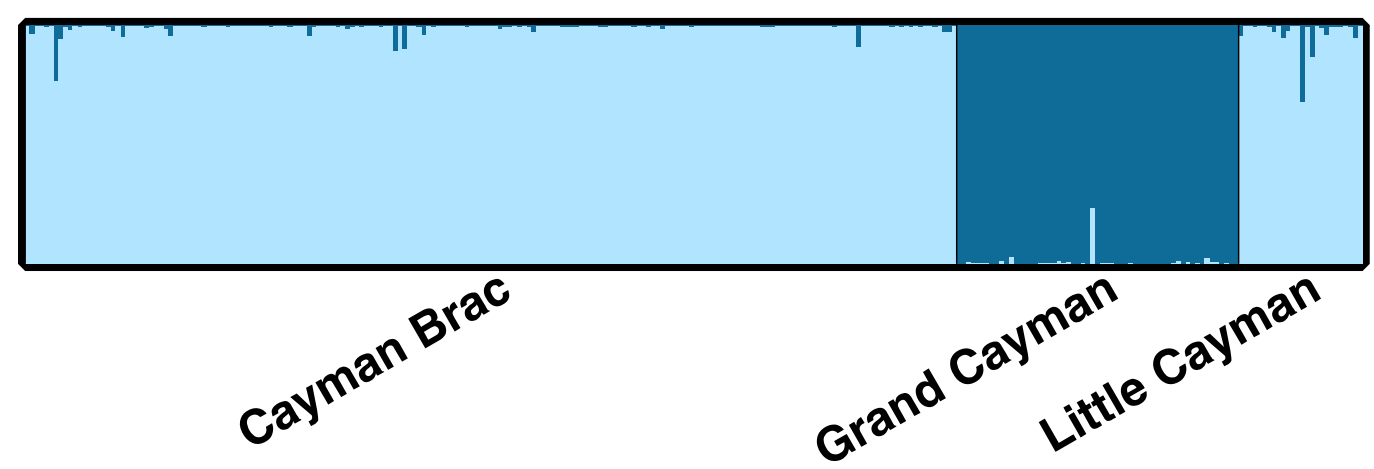


4492 Fig. S2 - Genetic relatedness among individuals and genetic groupings on the first two PC axes

7493 from a discriminant analysis of principal components (DAPC). Results are similar to the PCoA

9494 (Fig. 4) and STRUCTURE (Fig. S1) analyses in that Cayman Brac (yellow) and Little Cayman

495 (blue) are less differentiated (they form a single genetic cluster in the STRUCTURE analysis)

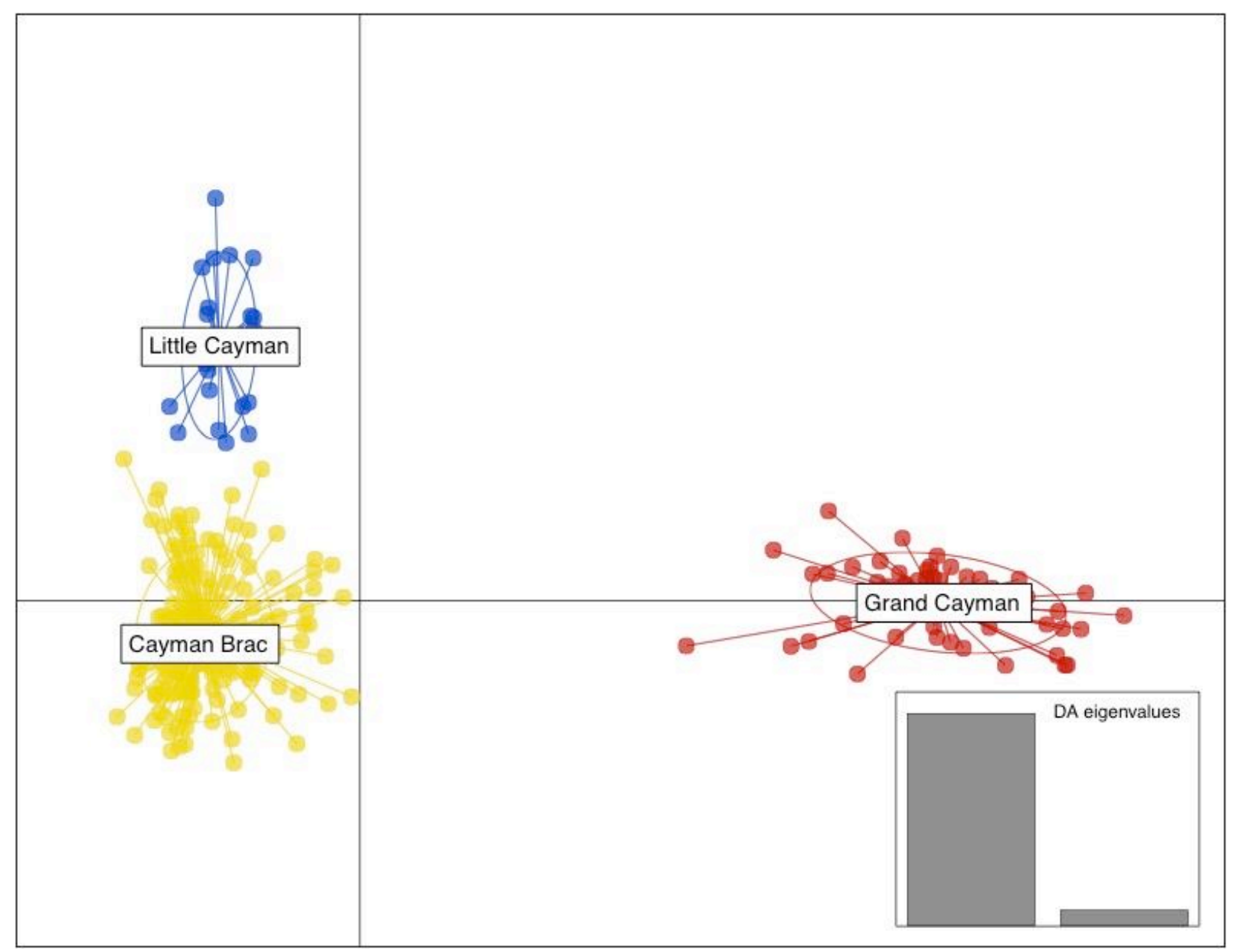


Fig. S3. Maximum likelihood phylogeny showing the relationships among ND2 haplotypes (540

502 bp) sampled on Cayman Brac, Grand Cayman, Little Cayman, and representative samples from

503 Florida and Cuba that show the invasive history. Little Cayman and Cayman Brac clades are

504 sister to samples from Eastern Cuba (Santiago de Cuba), whereas lizards from Grand Cayman

505 were introduced from non-native populations in south Florida, which originated from mutiple

506 sources across Cuba. The star indicates a red-dewlapped lizard (CB008) sampled on Cayman

507 Brac that has an intermediate nuclear genotype and Grand Cayman mtDNA haplotype. Bootstrap 508 values are shown for the major Cayman Island clades.

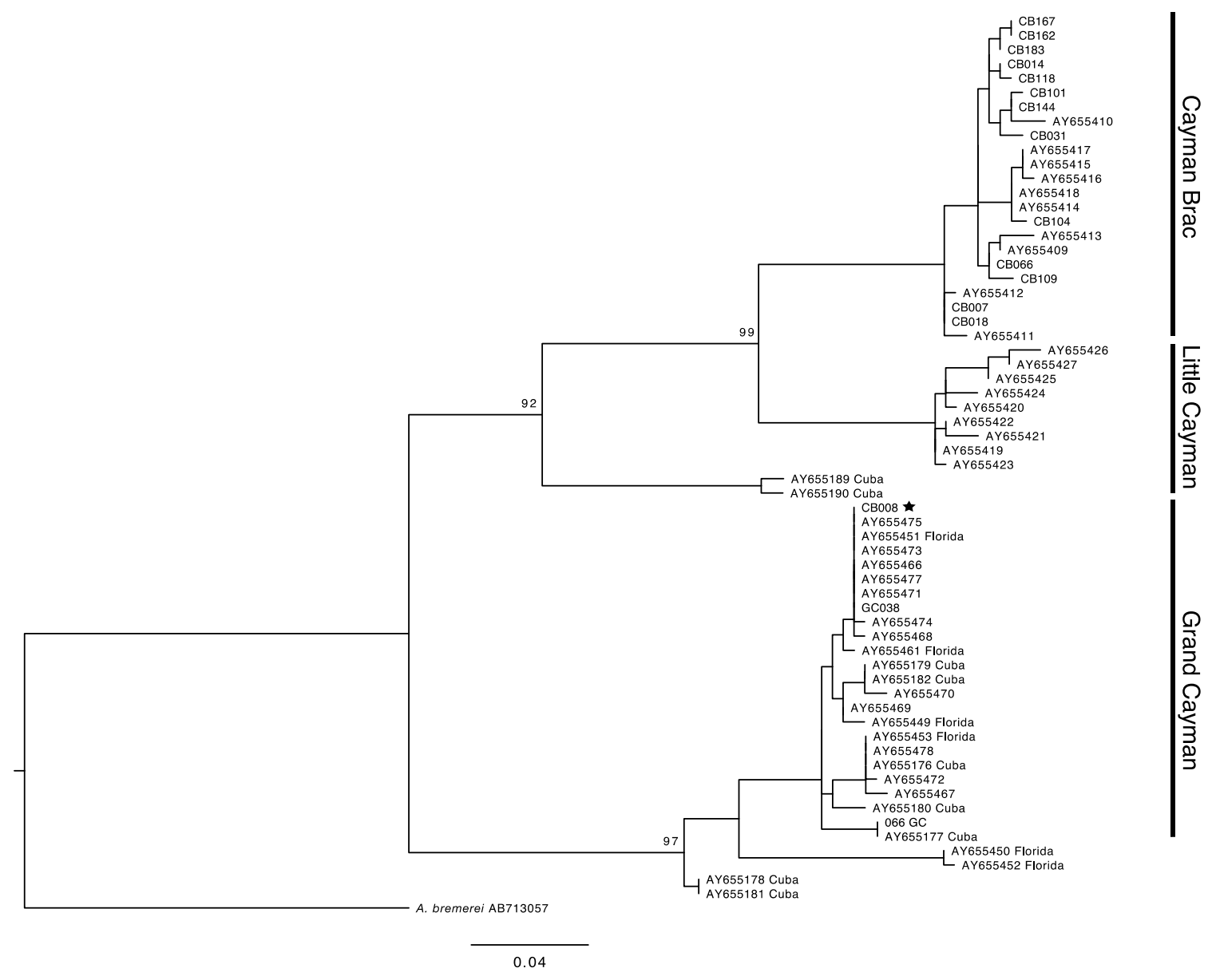

